\title{
Household Perspectives towards Integrated Management of Drinking Water in Faisalabad District, Punjab, Pakistan
}

\author{
Zahira Batool ${ }^{1}$ \\ Faiza Anjum² \\ Sadaf Faiz ${ }^{3}$ \\ Madieha Akram 4 \\ Muhammad Ibrahim 5 \\ ${ }^{1}$ Associate Professor, Department of Sociology, GC University, Faisalabad, Pakistan \\ ${ }^{2}$ Ph.D Scholar of Sociology, GC University, Faisalabad, Pakistan \\ ${ }^{3}$ M.Phil Scholar of Sociology, GC University, Faisalabad, Pakistan \\ ${ }^{4}$ Ph.D Scholar of Sociology, GC University, Faisalabad, Pakistan \\ ${ }^{5}$ M.Phil Scholar of Sociology, GC University, Faisalabad, Pakistan \\ Corresponding author's email: faizaanjum723@gmail.com
}

Doi:10.5901/mjss.2015.v6n5s2p503

\begin{abstract}
This study was aimed to examine the socioeconomic characteristics of the households and their linkages to the management of drinking water; the provision of education, income, water related cultural practices and utilization of health facilities. Furthermore, focused objective of the study was to examine the awareness about the causes of consequence water borne diseases, knowledge and preventive measures; and the importance of water quality as appropriate aspects to enhance integrated management of drinking water at household and community level in Faisalabad District. Cross-sectional study was conducted in urban areas of Faisalabad District of Punjab province in Pakistan. Triangulation was used to get significant detailed information and comprehensive interview schedule was used for the collection of information. The study identifies different factors effecting to the quality of water and sewerage system in most of the urban areas; are neither sufficient nor adequate and are often dysfunctional. Sewerage is usually carried in most of the urban areas by open surface flow drains, which ultimately discharge into streams and the river system, polluting the waterways and underground aquifers. The study also found that the contamination of drinking water caused highly contagious; people suffer from cholera, diarrhea, hepatitis and stomachache repeatedly; especially infants, children and pregnant women are affected more. It is suggested that to minimize the future drinking water shortages and undesirable environmental impacts, there is a need for more equitable sharing of water resources between society and nature is required.
\end{abstract}

Keywords: Household; Integrated management; Drinking water; and Health problems

\section{Introduction}

Water is a great gift of God for mankind and a grand source for food, health and other human purposes. About 97 percent of the world's water is salty and not fit for human consumption. Despite, remaining three percent constitute as fresh water; from which two percent of the water is in the form of glaciers and only one percent is available for human use (Umm-e-Habiba et.al, 2013; Bralower \& Bice, 2014). At present condition, about 1.1 billion people globally has inadequate access to pure water, and more than twice this number almost $50 \%$ (2.5 billion people) of the developing world's population have lack improved sanitation facilities (Water.org., 2015). Pure water and sanitation services with poor hygiene practices caused sickness that kills thousands of children every day; and around 1.8 million children under five years-old die every year caused parasitic and infectious diseases, most of them waterborne such as diarrhea, dehydration, cholera and hepatitis. Freshwater will become the most important strategic resource within the next 20 years; and essential for sustaining life and achieving sustainable development. As human use more water, less remains to maintain vital lake, wetlands and river. In developing countries, more than two million people die from drinking unsafe water, inadequate sanitation, associated waterborne diseases and poor hygiene; because of 90 to 95 percent of sewage 
and 70 percent of industrial wastes are dumped untreated into surface waters (UN-Water, 2014).

Pakistan, like northern China, is a water scarce country and the problem of water pollution is also growing at an alarming rate in Pakistan. The phenomenal growth in the country's population has unleashed unprecedented pressure on safe drinking water. Waterborne diseases such as dehydration, cholera, dysentery, stomachache, typhoid and hepatitis are commonly reported in both urban and rural areas.

In Pakistan, the total potential of ground water is 55 Million Acre Feet (MAF); and Punjab is about $79 \%$ and Sindh is about $28 \%$ of total area lay beneath the fresh groundwater (Pakistan Water Situational Analysis, 2001). Salty groundwater is generally put into drains and in some areas it is used by human beings which caused different stomach diseases. At the present ratio of population growth the population of Pakistan will be 229 million in 2025 (Zakria \& Muhammad, 2009). Quantity of untreated sewage and industrial effluents will grow in the same proportion if no remedial measure taken by the government of Pakistan. Urbanization is an increasing phenomenon over time in Pakistan and it also became a global phenomenon of our time. Ground water is a severe and costly threat to urban infrastructure and it has an invisible link with urbanization. There are many cities which are located in 'Landscape Lows'. The process of urbanization has become a serious issue globally for the management of fresh drinking water. It is estimated that by 2050 the urban' world population will be doubled by 6.4 billion; in low income countries which will increase the scarcity of fresh drinking water of both urban and rural areas of developing countries as well as Pakistan (Corcoran et.al, 2010).

In Faisalabad city, most of the urban family system is Nuclear family system which causes more the more use of water. Their major source of getting water is through WASA supply of water; but the quality of water is not good about this kind of water. We have a lot of water resource, but due to mismanagement, it has become serious issues. In Faisalabad city, diarrhea, dehydration, hepatitis, vomiting and food poisoning; and other water borne diseases are at highest incidence among the country (Akhtar, et al., 2005).

In this study, we will identify those factors which are affecting the drinking water and its management because it is the need of the day to take some important steps for drinking water management. Our main focus will be in the urban areas of Faisalabad District which are entirely affected by impure drinking water which caused a number of diseases.

\subsection{Objectives of the Study}

- To study the socioeconomic characteristics of the respondents.

- To identify the factors affecting integrated management of drinking water at household level.

- To examine the effects of drinking water on their health status.

\subsection{Hypothesis of the Study}

- Family type and integrated management of drinking water are associated.

- The monthly income of the family and integrated management of drinking water are associated.

- The education of the respondents and integrated management of drinking water are associated.

\section{Research Methods}

The present study was conducted to examine the integrated management and treatment of drinking water at household level. The people of urban areas of Faisalabad District are highly affected by unsafe drinking water. The universe of the present study was the urban areas of Faisalabad District. In this study the mothers were selected to collect the information. Multi-stage sampling technique was used to select the final sample. The total number of towns in Faisalabad District is about 8. At the first stage, two towns namely Jinnah town and Lyallpur town were taken by using the simple random sampling technique. At the second stage, 4 urban union councils were selected randomly from the selected towns. The total number of urban union councils was 30 and 22 in Jinnah town and Lyallpur town respectively. At the final stage, a total number of 200 respondents (i.e. mothers) were randomly picked from the selected union councils. The responses were collected through a well-designed interviewing schedule. The gathered data was analyzed through various techniques such as descriptive, bivariate and multivariate statistics. In descriptive analysis, frequency distribution and percentages were used to describe the data. The relationship/association among the independent (socioeconomic characteristics) and the dependent (integrated management of drinking water) variables was examined through applying chi-square and gamma statistics. The relative importance of independent variables in explaining dependent variable was based upon multivariate analysis through applying regression statistics. 


\section{Results and Discussion}

Table 1. Distribution of the Respondent's Socioeconomic Characteristics $(n=200)$

\begin{tabular}{|l|c|l|c|}
\hline Categories & N (Percentage) & Categories & N (Percentage) \\
\hline Age (Years) & & Type of Family & \\
\hline Up to 29 & $38(19.0)$ & Nuclear & $114(57.0)$ \\
\hline $30-39$ & $78(39.0)$ & Joint & $86(43.0)$ \\
\hline $40-49$ & $48(24.0)$ & Monthly Family Income (Rs.) & $51(25.5)$ \\
\hline 50 and above & $36(18.0)$ & Up to 10000 & $61(30.5)$ \\
\hline Education (No. of years) & & $10001-20000$ & $48(24.0)$ \\
\hline 0 & $20(10.0)$ & $20001-30000$ & $40(20.0)$ \\
\hline 5 & $66(33.0)$ & 30001 \& above & $163(81.5)$ \\
\hline 10 & $48(24.0)$ & Occupation & $37(18.5)$ \\
\hline 12 & $42(21.0)$ & House wife & Job \\
\hline 14 \& above & $24(12.0)$ & Job & \\
\hline
\end{tabular}

\subsection{Socioeconomic Characteristics of the Respondents (age, education, type of family and family income).}

Table 1 reveals that the majority 39.0 percent of the respondents belonged to age category 30-39 years; and 10 percent of the respondents were illiterate. Attitude towards female education is very restricted and they socially and culturally bound. Furthermore, public and private educational resources are very scared as compared to the number of beneficiaries. Public concern towards female education is very poor and full of superstition believes that women have no right to get education otherwise they will let down over male rights. About 33.0 percent of the respondents had up to five years schooling, it shows that its majority of the females having primary education. Data shows the picture of urban female and the majority of them were belonged to labor families. Due to poor socioeconomic strata of people have low trends of female education rather they prefer their early marriages. About 24.0 and 21.0 percent of the respondents had 10 and 12 years of schoolings respectively. Only 10.0 percent of the respondents had 14 and above years education. There are several reasons like lack of income resources, school distance and cultural values of early marriages. Parents desire to wed their daughter over schooling. Pakistani women's literacy rate is the lowest in the region. The educational rate for urban women is more than five times than for rural women. UN (1995) reported that in Pakistan, the women's access to education, employment and property remains considerably lower as compared to men's. Pakistani society is predominantly patriarchal and women's participation in outside related work activities conditioned with the permission of family male heads.

In Pakistan there are three types of families' nuclear, joint and extended, but the most common form of families is joint and nuclear. In cities most families are living in a nuclear family system and joint family rapidly changing into nuclear families due to changes. In rural areas, although people are also giving preference to live in nuclear family to address their socioeconomic needs properly. The results indicate that 57.0 percent of the respondents belonged to joint family and 43.0 percent of the respondents belonged to nuclear family.

Family income is an important factor to explain the provision of household facilities. Monthly income at family level depicts a picture of available facilities, eating habits and management of the household. If the families have high prestige of income, they could manage better their food patterns and health related issues. The data show that the majority 30.0 percent of the family's monthly income was in the category of 10001 to 20000 Rs (see table 1). Despite, with low family income they rely on the water source (WASA Municipal) that is available in their existing territory; cannot afford the other sources (Mineral water; Filter water) in these expensive days. Most 81.5 percent of the respondents were housewife.

Table 2. Distribution of the Respondents according to the Utilization of Water $\quad(n=200)$

\begin{tabular}{|l|c|l|c|}
\hline Categories & N (Percentage) & Categories & N (Percentage) \\
\hline Availability of water sources (No.) & \multicolumn{2}{|l|}{ Satisfaction with quality of water } \\
\hline \hline One & $48(24.0)$ & To a great extent & $12(6.0)$ \\
\hline Two & $124(62.0)$ & To some extent & $68(34.0)$ \\
\hline Three and above & $28(14.0)$ & Not at all & $120(60.0)$ \\
\hline Type of sources & & Reasons of bad quality of water \\
\hline
\end{tabular}




\begin{tabular}{|l|c|l|c|}
\hline Electric Pump & $3(1.5)$ & Bad smell & $120(60.0)$ \\
\hline Mineral water & $19(9.5)$ & Salty water & $58(29.0)$ \\
\hline Canal bank pump & $48(24.0)$ & Dirty water & $22(11.0)$ \\
\hline WASA Municipal & $130(65.0)$ & Measures (to improve the quality) \\
\hline Water storage system & & No & $46(23.0)$ \\
\hline Concrete tank & $28(14.0)$ & Filtration & $58(29.0)$ \\
\hline Fiberglass tank & $146(73.0)$ & Boiling & $96(48.0)$ \\
\hline Drum & $26(13.0)$ & & \\
\hline
\end{tabular}

\subsection{Water' Sources and Types of Water Sources}

The data shows majority 62.0 percent of the respondents had two types of sources. Poor quality of water comprises bad smell; salty water and mud mix are multi reasons having more than one source of water.

Drinking water is the main factor to cause digestive system and allergy complications which cause mal-absorption. About 65.0 percent of the respondents used WASA Municipal/piped water, 24.0 percent used bank canal water. Naqvi (2005) studied that WASA/Municipal water in Faisalabad became contaminated after a sewage leak that seeped into the water system. A hospital official said he expects the number of cases to rise. About 9.5 percent of the respondents used mineral water. Due to lack of pure water sources people purchased, but this is a very low ratio because people cannot afford to purchase water. Every person needs at least four liter water within 24 hours and the price of 1 liter is 25 rupees so with large family size and low income, it is difficult to access water. Only 1.5 percent used an electric pump for drinking water; because water access from the ground is very low and not able to drink.

\subsection{Water Storage System}

The water storage system is very typical in the urban areas of Pakistan; it's the emergent need of people to store water in different ways. According to data 14.0 percent of the respondents had a concrete tank which was just part of the building. About 73.0 percent used fiberglass tank, and 13.0 percent used drum. In last two options people were living very congested homes with lower socioeconomic strata and could not afford to have concrete tank. The quantity and quality of unsafe drinking water, poor sanitation system and unhygienic conditions cause illness and reducing working hours' ability; International experience indicates that the lack of attention to water, sanitation and hygiene issues is amongst the most prominent sources of backwardness in the developing world (Ali, 2010).

\subsection{Satisfaction with Quality of Water}

Only 6.0 percent of the respondents were satisfied with the quality of water to a great extent, but 34.0 percent were satisfied to some extent. About 60.0 percent of the respondents were unsatisfied with water smell, its color and heaviness. Children's Health Protection (2001) pointed out that contaminants (gasoline and pesticides), caused the water to taste and smell strange, and disease-causing organisms may not be detectable, potentially harm for developing brain or immune system. A Pakistan water supply system developed, but still not purified. Water piped are along with the sewerage pipes along with water piped contaminated water.

\subsection{Reasons of Bad Quality of Water and Measures (to improve the quality)}

It is estimated that 23.0 percent of the respondents told that they use water as such come from WASA Municipal, electric pump and tape. It is clear from the empirical evidence that drinking water in District Faisalabad is of harmless ingredients which need treatment to make it hygiene. About 29.0 percent of the respondents told that they have attached filters with water tank. It is difficult to afford filter for all public which is quite expensive. Most of 48.0 percent of the respondents boiled water before using but most of them did not know how much time they have to boil? So that water treatment has adverse effects over their health. 
Table 3. Distribution of the Respondent's Perception about Fresh Water $(n=200)$

\begin{tabular}{|l|c|c|c|c|}
\hline Responses & Strongly Agree & Agree & Disagree & Strongly Disagree \\
\hline & $\mathbf{N}$ (Percentage) & $\mathbf{N}$ (Percentage) & $\mathbf{N}$ (Percentage) & N (Percentage) \\
\hline Limited fresh water resources & $84(42.0)$ & $96(48.0)$ & $18(9.0)$ & $2(1.0)$ \\
\hline Fresh water is a serious issue & $88(44.0)$ & $98(49.0)$ & $12(6.0)$ & $2(1.0)$ \\
\hline People are careless in using water & $42(21.0)$ & $80(40.0)$ & $66(33.0)$ & $12(6.0)$ \\
\hline
\end{tabular}

\subsection{Perception about Fresh Water}

In spite having all water related needs but people waste water just foe nothing. Here data displays the people' attitude towards fresh water, about 42.0 and 48.0 percent of the respondents expressed that there are limited fresh water resources strongly agree and agree respectively. It shows that present water sources are scared and it is not fulfilling the need of the people. Fresh water is a serious issue in the globe as well as in Pakistan; almost half percent also agrees with the point of view that fresh water is a serious issue of our country but does not meet its ends. According to primary data, about 40.0 percent and 21.0 of the respondents expressed their views with agree and strongly agree respectively that people careless in using the water as tapes are opened; water pipes are damaged and burst, overuse of water for animal bath and house cleaning.

Table 4. Distribution of the Respondents according to the Pipeline Problems and Waterborne Diseases.

\begin{tabular}{|l|c|l|c|}
\hline Categories & N (Percentage) & Categories & N (Percentage) \\
\hline Pipeline problems & & Waterborne diseases & \\
\hline Fungus & $148(74.0)$ & \multirow{2}{*}{ Vomiting and food Poisoning } & $72(36.0)$ \\
\hline Leakage & $26(13.0)$ & & $32(16.0)$ \\
\hline Rust & $16(8.0)$ & Diarrhea & $22(11.0)$ \\
\hline Dust & $10(5.0)$ & Cholera & $18(9.0)$ \\
\hline & & Hepatitis & $56(28.0)$ \\
\hline
\end{tabular}

\subsection{Pipeline Problems and Waterborne Diseases}

The particles of dust, plastic and fungus mixed in water supply because of the poor quality pipelines that remain unchecked due to the heedlessness. In Pakistan, about 80 percent of all infectious diseases are waterborne; over 200,000 children die every year due to it (Rosemann, 2005). Pipeline issues are also discussed by the respondents, as 74.0 percent of the respondents said that drinking is included with fungus, only 8.0 percent stated that rust is included in the water, but around 5.0 percent reported about dust and remaining complained about water leakage (see table 4). In Pakistan, open sewage drains and drinking water supply lines in the streets are laid side by side. It resulted in; poor connections cause a lot of leakage.

This table also identifies the different health problems, the respondents faced. About 36.0 percent of the respondents suffered from vomiting and food poising; while 16.0 percent suffered from diarrhea (abdominal pain); 11.0 percent from cholera and remaining 9.0 percent of hepatitis (including skin allergies/ yellow fever). Children's Health Protection (2001) also pointed out that poor quality water causes disease-causing organisms; he/she may come down with symptoms similar to the stomach ache, diarrhea, nausea, vomiting, and also may cause yellow fever and skin allergies.

Table 5. Values of Chi-Square and Gamma Tests; Giving the Relationships of Different Socioeconomic and Integrated Management of Drinking Water Variables.

\begin{tabular}{|l|c|c|}
\hline Variables & Chi-square (sig. level) & Gamma (sig. level) \\
\hline Family Type (Nuclear Family) $\mathbf{X}_{1}$ & $39.05(0.001)$ & $0.223(0.001)$ \\
\hline Family Income $\mathbf{X}_{2}$ & $48.89(0.000)$ & $0.575(0.000)$ \\
\hline Education $\mathbf{X}_{3}$ & $85.24(0.000)$ & $0.654(0.000)$ \\
\hline
\end{tabular}




\subsection{Association between the Family Type and Integrated Management of Drinking Water}

In Pakistan two types of family structure: nuclear and joint family is common. The nuclear family system comprises father, mother, children and they live together. Father and mother play a significant and governing role with respect to the wellbeing and provision of household facilities to family members. Nuclear family style is increasing due to increasing modernization, urbanization, and individualism.

This table reflects the relationship between the family type and integrated management of drinking water. The value of chi-square (39.05) depicts a strong association at the 1 percent level of significance between type of family and level of management of drinking water. The value of gamma shows a strong positive association between these variables. It shows that respondents those belonged to nuclear families had better integrated management of drinking water as compared to respondents who belonged to joint families. The family structure in each country depends upon its culture and living style. As study indicates the respondents belonged to the nuclear family, they had better management of drinking water because of less number of family members than joint family structure. Keeton (2007) revealed that nuclear family often does better, due the fact that members in nuclear families have easy access to two parents earning income. Normally, they are well off economically and this helps to have a healthy and safe environment, good schooling, good health care and nutrition.

\subsection{Association between the Family Monthly Income and Integrated Management of Drinking Water}

It is a very important variable to determine the provision of household facilities. Income at family level shows a variety of household facilities, eating habits and management of the household. It also reviews the effect of livings and a variety of other factors. The result of chi-square (48.89) shows a highly significant relationship between monthly income of the family and management of drinking water. A positive relationship among the variables is viewed by the value of gamma $(0.57)$ that indicates as income increases, water management at household level is made better. Data depicts that woman who belonged to high income families had good managerial skills to manage water at their household level. UNESCAP (2007) depicted that family monthly income is an effective contribution to children and women's health development. Better economic conditions helps in utilizing of household facilities and minimizing biases against gender equality and nutrition. Good family wages and promotions are another aspect for ensuring more opportunity to efficiently contribute in socioeconomic aspects.

\subsection{Association between the Education of the Respondents and Integrated Management of Drinking Water}

Educated women are the main agent for change as far as domestic issues. Those countries which have a high female literacy rate, have better household management, good health, curative reproductive problems and longer life expectancy, and vice versa. The chi-square value (85.24) depicts a highly association between the respondent's education and integrated management of drinking water. A strong positive relationship among the variables is viewed by the value of gamma (0.65). The woman, who was educated, had higher integrated management of drinking water. Bailey (2003) studied that there is an inverse relationship between the variables; as an increase in the level of education has causing effect to increase in integrated management of drinking water. He also concluded that the increase in integrated management of drinking water resulting from better socioeconomic conditions improved educational performance.

Table 6. Standardized Regression Coefficients, $t$ Values and Level of Significance of Socioeconomic and Integrated Management of Drinking Water Variables Regressed on Integrated Management of Drinking Water at Household Level.

\begin{tabular}{|l|c|c|c|}
\hline Variables & Standardized Coefficients & $\mathrm{T}$ & Sig. \\
\hline Family Type (Nuclear Family) $\mathbf{X}_{1}$ & .189 & 2.833 & .005 \\
\hline Family Income $\mathbf{X}_{2}$ & .487 & 4.282 & .000 \\
\hline Education $\mathbf{X}_{3}$ & .295 & 3.534 & .001 \\
\hline Availability of Water Sources $\mathbf{X}_{4}$ & -.004 & -.049 & .019 \\
\hline Satisfaction with the Quality of Water $\mathbf{X}_{\mathbf{5}}$ & -.548 & -4.211 & .000 \\
\hline Water Utilization $\mathbf{X}_{6}$ & .830 & 5.968 & .000 \\
\hline Behavioral Changes to improve the Quality of Drinking Water $\mathbf{X}_{7}$ & .024 & .119 & .050 \\
\hline Water Diseases $\mathbf{X}_{\mathbf{8}}$ & -.114 & -1.826 & .010 \\
\hline Bad Quality of Water Effect on Management $\mathbf{X}_{\mathbf{9}}$ & -.136 & -1.978 & .051 \\
\hline
\end{tabular}




\begin{tabular}{|c|c|c|}
\hline Hygienic Conditions of Water Storage System $\mathrm{X}_{10}$ & -.070 & \begin{tabular}{|l|l|}
-.888 & .001 \\
\end{tabular} \\
\hline Pipelines Issues Affect $X_{11}$ & -.175 & \begin{tabular}{|l|l|}
-2.993 & .003 \\
\end{tabular} \\
\hline 0.762 & & \\
\hline
\end{tabular}

\subsection{Socioeconomic and Integrated Management of Drinking Water Variables Regressed on Integrated Management of Drinking Water at Household Level.}

In the above table standardized regression coefficients of every predictive variable are discussed along with standard error and the level of significance are given. Practices for water collection, storage, handling and types of storage containers, water quality its treatment, utilization and behavioral changes are the dimensions of the index as response variables (integrated management of drinking water). The regression coefficient beta is used to identify the significance of the independent variable. Higher regression value shows the elevated importance of that variable. It is evident from the table that education enhances the integrated management of drinking water. Value of regression coefficients 0.295 means to increase in one year of schooling respondents performed well in water management skills 0.295 units, significant at 0.001, level. Tambekar, et al (2008) found that socioeconomic and cultural status is highly significant and contributory factors of the management of drinking water at a household level and women education have profound impact water storage and its hygiene conditions. Respondent's type of family (nuclear family), family monthly income, behavioral changes and different sources of water have a positive sign for their respective regression coefficient indicating a direct relationship with the dependent variable. Type of family has a significant value for regression coefficient. It emerges that integrated management of drinking water is affected up to a great extent by nuclear family. Among these factor family income has a coefficient of regression value 0.487 that reveals an increase in income of one thousand rupees caused better management.

Our results are supported by Clasen, et al (2006) stated that good socioeconomic strata have more knowledge about water management and its consumption. Behavioral changes also depict an important role in increasing the water management at household level and showing a coefficient value significant at the 5 percent level of significance. In urban areas of Punjab, pure drinking water is scared and people had multiple sources to be satisfied with the quality of water. The study shows that those respondents who had proper income, their availability of water sources were more than lower socioeconomic strata. In the model use of hygienic conditions for quality of stored water is found to have significant value of regression coefficient 0.070 . It is a fact from the table that non-availability of water reduces the integrated management of drinking water. Value of regression coefficients 0.004 means non-availability of water increased the risk of having low management ability by 0.004 units, significant at 0.019 levels. It is also evident from the model figures that low satisfaction with the quality of water, poor quality of water and water pipeline issues reduce the capacity of water management at household level. Its values of regression coefficients show the risk trends and inverse inference in the performance of water management at domestic level.

WHO (1996) investigated that all cities, a distinction can be made between different income groups (high, middle and low), between the different types of urban areas they live in and hence urban community had multiple problems as pipeline issues, high water demand and non-availability of pure water which directly affect their households needs and management.

Fitness of the model is estimated through the coefficient of determination $\mathrm{R}^{2}$ indicating the contribution of the independent variables in the variation of the dependent variable. In the table the value of $R^{2}(0.762)$ indicates that independent variables explained 76 percent variation in the integrated management of drinking water at household level. In the social sciences the value of $\mathrm{R}^{2}$ is more than 0.40 , the model is considered as a best fit model reflecting that predicting variable in the regression model are relevant and appropriate for the issue or problem being investigated (Zafar, 1993). For this study the value of $\mathrm{R}^{2}$ is 0.762 is an indication that explanatory variables given in the model which best explain the response management variable.

Model: $Y=\alpha+b_{1} X_{1}+b_{2} X_{2}+b_{3} X_{3} \ldots+b_{n} X_{n}+e$

Fitted Model:

Integrated Management of Drinking Water $=18.21+0.189_{1}+0.487_{2}+0.295_{3}-0.004 \mathrm{X}_{4}-0.548 \mathrm{X}_{5}+0.830 \mathrm{X}_{6}+$ $0.024 X_{7}-0.114 X_{8}-0.136 X_{9}-0.070 X_{10}-0.175 X_{11}$

\section{Conclusion}

This study discussed an analysis of drinking water treatment and management in the Faisalabad city. It also identifies 
different factors effecting to the quality of drinking water and the resultant health impacts. It is observed through a primary survey that the ever growing population and socioeconomic activity are leading to water stress and shortages in several parts of the City. It was pointed out that water supply and sewerage system in most of the urban areas are neither sufficient nor adequate and are often dysfunctional. Sewerage is usually carried in most of the urban areas by open surface flow drains, which ultimately discharge into streams and the river system, polluting the waterways and underground aquifers. The study found that the infectious particles of dust and fungus mixed with drinking water due to the unhygienic conditions of water supply pipelines; having negative impact on their health status.

For ensure the purifying of drinking water, there is a need to improve the condition of pipeline supplies. Despite, a good water management policy should remove the multiple-barriers for the protection of water. These barriers include: water treatment and management; sources, distribution and storage system; monitoring, mobilizing and awareness. This also needs more detailed analysis of the household perspectives towards integrated water resources management at various spatial, temporal and human scales and their incorporation into water policy and water sector programs.

\section{References}

Akhtar, N., Jamil, A., Noureen, H., Imran, M., Iqbal, I., \& Alam, A. (2005). Impact of Water Pollution on Human Health in Faisalabad City Pakistan. Journal of Agriculture \& Social Sciences, 1(1): 43-44.

Ali, S.M. (2010). Development: Pakistan's Growing Water Challenges. [Online] Available: http://archives.dailytimes.com.pk/editorial/06Apr-2010/development-pakistan-s-growing-water-challenges-syed-mohammad-ali.

Bailey, B. (2003). Synthesis of Lessons Learned of Donors in Fighting Corruption. Network on Governance. [Online] available: unpan1.un.org/intradoc/groups/public/.../unpan016841.p..

Bralower, T., and Bice, D. (2014). Distribution of Water on the Earth's Surface. Copyright @ 2014. The Pennsylvania State University. [Online] available: https://www.eeducation.psu. edu/earth 103 /node/735.

Children's Health Protection. (2001). Children's Health in the Aftermath of Floods. Environmental Protection Agency Office of the Administrator Office of Children's Health Protection, North Washington, DC. [Online] available: www2.epa.gov/...n/2001childrens-health-protection.

Clasen, T., Roberts, I., Rabie, T., Schmidt, W., and Cairncross, S. (2006). "Interventions to Improve Water Quality for Preventing Diarrhea". Cochrane Database of Systematic Reviews (3). [Online] available: www.cochrane.org/.../INFECTN_interventions-to...

Corcoran, E., Nellemann, C., Baker, E., Bos, R., Osborn, D. \& Savelli, D. (eds). (2010). Sick Water? The Central Role of Wastewater Management in Sustainable Development. A Rapid Response Assessment. United Nations Environment Programme, UNHABITAT, GRID-Arendal. [Online] available: www.unep.org/pdf/SickWater_screen.pdf.

Keeton, C. (2007). Nuclear Family is Always Best for Kids: Love and Money better Ingredients for Success than Structure. The Times: Nov 18, 2007.

Naqvi. (2005). Survey and Determination of Resistance in Mosquitoes and Houseflies of Karachi and Faisalabad. Technical Report, PSF Project No.S-Ku/Bio-161, pp. 1-132.

Pakistan Water Situational Analysis. (2001). [Online] available: waterinfo.net.pk/sites.../Pakistan \%20Water\%20Situation\%20Analysis. $\mathrm{pd} . .$.

Rosemann, N. (2005). Drinking Water Crisis in Pakistan and the Issue of Bottled Water: The Case of Nestlé's 'Pure Life'. Swiss Coalition of Development Organizations. [Online] available: www.alliancesud.ch/en/policy/climate/downloads/nestle-pakistan.pdf.

Tambekar, D.H., Gulhane, S.R., Jaisingkar, R.S., Wangikar, M.S., Banginwar, Y.S. \& Mogarekar, M.R. (2008). Household Water Management: A Systematic Study of Bacteriological Contamination between and Point of Use. American-Eurasian J. Agric. And Environ. Sci., 3(2): 241-246.

Umm-e-Habiba., Taj, L., Farid, M., Anwar-ul-Haq, M., Sharif, N., Farheen, H., and Sharif, N. (2013). Quality Analysis of Ground Water Resources of Paharang Drain Faisalabad City. International Journal of Science, Environment and Technology, 2(6): 1175 - 1184.

United Nations'. (1995). Women's Indicators and Statistics, Pakistan Gender Indicators- Projections for 1995. [Online] available: www.danielpipes.org/comments/163246.

UN-Water. (2014). The United Nations Inter-agency Mechanism on all Freshwater Related Issues, Including Sanitation. [Online] available: http://www.unwater.org/statistics/statistics-detail/fi/c/ 211800/.

UNESCAP. (2007). The Fourth Central Asia Medical Women Association Conference, Bangkok, Thailand, 14-16 June 2007. [Online] available: apps.who.int/iris/.../RD-speeches_14June 07.pd...

Water.org. (2015). Billions Affected Daily by Water and Sanitation Crisis. Copyright (C) 1990-2015 Water.org. [Online] available: http://water.org/water-crisis/one-billion-affected/.

WHO. (1996). Water Supply and Sanitation Sector Monitoring Report - Sector Status as of December 1994. [Online] available: http://www.africanwater.org/coverage_1996.htm.

Zafar, M.I. (1993). The Correlates of Contraceptive and Fertility Behavior within the Framework of Socio-Cultural Ideology: A Case Study of two Urban Centers of Pakistan. An un-published Ph.D Thesis, University of Exeter, United Kingdom.

Zakria, M. \& Muhammad, F. (2009). Forecasting the Population of Pakistan using ARIMA Models. Pak. J. Agri. Sci., 46(3): 214-223. 